\title{
Penerapan Pembelajaran Matematika Realistik UnTUK MENingKatKan KEMAMPUAN AdAPTIVE REASONING SiSWA
}

\section{IMPLEMENTATION OF REALISTIC MATHEMATICS EDUCATION TO ENHANCE ADAPTIVE REASONING STUDENTS}

\author{
Ida Nuraida \\ Jurusan Pendidikan Matematika, Universitas Galuh \\ Jl. R.E. Martadinata No. 150, Ciamis, Mekarjaya, Jawa Barat, Indonesia \\ ida.nuraidamath@gmail.com
}

\begin{abstract}
Abstrak
Penelitian ini dilatarbelakangi oleh adanya kemampuan adaptive reasoning siswa yang masih rendah. Untuk mengatasi masalah tersebut, peneliti menggunakan pembelajaran Realistic Mathematics Education karena tahap pembelajaran ini mendukung pada indikator kemampuan adaptive Reasoning siswa. Tujuan penelitian ini adalah untuk mengetahui peningkatan dan pencapaian kemampuan adaptive Reasoning siswa melalui pendekatan pembelajaran RME. Metode yang digunakan dalam penelitian ini adalah metode kuasi eksperimen dengan desain penelitian the nonequivalent pretest-posttest control group design. Populasi dalam penelitian ini adalah seluruh siswa kelas IX SMP Negeri 5 Kota Tasikmalaya Tahun Pelajaran 2015/2016. Pengambilan sampel dalam penelitian ini dilakukan dengan purposive sampling dengan kelas IXF sebagai kelas eksperimen yaitu pembelajaran RME dan kelas IXG sebagai kelas kontrol yaitu pembelajaran biasa yang masing-masing terdiri dari 32 orang siswa. Teknik pengumpulan data yaitu menggunakan instrumen tes berupa uraian berjumlah 4 soal. Teknik analisis data yang digunakan untuk menguji hipotesis adalah uji t dan uji Mann-Whitney dengan taraf signifikansi $5 \%$. Berdasarkan hasil penelitian, pengolahan data, analisis data dan pengujian hipotesis diperoleh kesimpulan bahwa Peningkatan adaptive reasoning siswa kategori PS (atas dan menengah) yang memperoleh pembelajaran RME lebih baik daripada siswa yang memperoleh pembelajaran Konvensional.

Kata Kunci: Matematika Realistik, Adaptive Reasoning.
\end{abstract}

\begin{abstract}
This research is motivated by the ability of adaptive reasoning of students who are still low. To overcome these problems, researchers use Realistic Mathematics Education because this learning stage supports the indicators of Adaptive Reasoning ability of students. The purpose of this research is to know the improvement and achievement of Adaptive Reasoning ability of students through learning approach of RME. The method used in this research is the quasi experiments with the nonequivalent design study of pretest-posttest control group design. The population in this research is all students of class IX SMP Negeri 5 Kota Tasikmalaya Lesson Year 2015/2016. Sampling in this research is done by purposive sampling with class IXF as experiment class that is learning of RME and class IXG as control class that is conventional which each consist of 32 students. Technique of collecting data that is using test instrument in the form of description is 4 problems. Data analysis techniques used to test the hypothesis are $t$ test and Mann-Whitney test with significance level of 5\%. Based on the results of research, data processing, data analysis and hypothesis testing, it is concluded that the increase of adaptive reasoning of (upper and middle) PS category students who gain RME learning is better than students who get conventional learning.

Keyword: Realistic Mathematics Education, Adaptive Reasoning.
\end{abstract}




\section{Pendahuluan}

Menurut Soedjadi (2004), pendekatan matematika realistik atau dikenal dengan Realistic Mathematic Education (RME) dikembangkan berdasarkan pandangan Freudenthal yang berpendapat bahwa matematika merupakan kegiatan manusia yang lebih menekankan aktivitas siswa untuk mencari, menemukan, dan membangun sendiri pengetahuan yang diperlukan sehingga pembelajaran menjadi terpusat pada siswa.

Gravemeijer (2004) Pembelajaran matematika menggunakan pendekatan matematika realistik tidak dimulai dengan mengajarkan matematika formal, melainkan pembelajaran mengarahkan siswa untuk menghargai dan memahami arti pentingnya matematika sebagai aktivitas manusia. Proses pembelajaran dilakukan secara bertahap melalui pengetahuan awal matematika yang telah siswa miliki, mempresentasikan masalah dan hasil yang diperoleh melalui matematisasi vertikal dan horizontal disebut progresif matematis. Setiap masalah kontekstual dirancang untuk melibatkan siswa dalam berwacana matematis, mengeksplorasi, mengembangkan strategi mereka sendiri dalam memecahkan masalah melalui alat matematika yang tepat, bekerja secara kolaboratif, menemukan konsep dan objek matematika sendiri melalui proses penemuan terbimbing

RME adalah pendekatan pengajaran yang bertitik tolak dari hal-hal yang 'real' bagi siswa, menekankan keterampilan proses, berdiskusi dan berkolaborasi, berargumentasi dengan teman sekelas sehingga mereka dapat menemukan sendiri konsep dalam menyelesaikan masalah matematika. Salah satu prinsip utama RME menurut Rianasari (2012) adalah Guided Reinvention atau penemuan terbimbing. Menurut prinsip reinvention bahwa dalam pembelajaran matematika perlu diupayakan agar siswa mempunyai pengalaman dalam menemukan sendiri berbagai konsep, prinsip atau prosedur, dengan bimbingan guru.

Freudenthal (1990) berpendapat bahwa matematika merupakan kegiatan manusia yang lebih menekankan aktivitas siswa untuk mencari, menemukan, dan membangun sendiri pengetahuan yang diperlukan sehingga pembelajaran menjadi terpusat pada siswa. Treffer (dalam Suryadi dan Suratno, 2014) mencoba memfomulasikan proses matematisasi, dalam konteks pendidikan matematika, menjadi dua tipe yakni matematisasi horizontal dan vertikal.

Pembelajaran matematika sekolah harus mampu mengembangkan kecakapan matematika karena kecakapan matematika merupakan salah satu tujuan yang harus dicapai dalam menghadapi jaman modern (Hudojo, 2004). Menurut Killpatrick et al (2001) pembelajaran matematika sekolah harus mampu mengembangkan kecakapan matematika yang terdiri dari lima untaian yaitu: 1) Conceptual understanding (pemahaman konsep): pengetahuan tentang konsepkonsep, operasi dan relasi matematis; 2) 
Procedural fluency (penerapan prosedur): kemampuan untuk menerapkan prosedur secara akurat, efisien dan tepat; 3) Strategic competence (kompetensi strategis): kemampuan untuk merumuskan, mempresentasikan, dan menyelesaikan masalah; 4) Adaptive reasoning (penalaran adaptif): kemampuan berpikir logis dan reflektif serta kemampuan menjelaskan; 5) Productive disposition (disposisi produktif): kecenderungan untuk memandang matematika sebagai sesuatu yang bermakna, berguna dan bernilai, serta keyakinan terhadap ketekunan dan potensi diri sendiri. Satu kecakapan dari lima kecakapan tersebut merupakan kecakapan yang mendasar terkait penalaran yaitu kemampuan Adaptive reasoning.

\section{Metode}

Penelitian ini merupakan studi "KuasiEksperimen". Pada studi ini subjek tidak di kelompokkan secara acak, tetapi keadaan subjek diterima sebagaimana adanya (Ruseffendi, 2010). Pemilihan studi ini didasarkan pertimbangan bahwa kelas yang ada telah terbentuk sebelumnya dan tidak mungkin dilakukan pengelompokan siswa secara acak. Kedua kelompok tersebut sama-sama memperoleh pretes dan postes, akan tetapi kelompok eksperimen saja yang diberikan treatment.

Tujuan penelitian ini adalah untuk memperoleh gambaran tentang penggunaan pembelajaran RME untuk meningkatkan kemampuan adaptive reasoning siswa dalam pembelajaran matematika yang melibatkan dua kelompok siswa, yaitu kelompok eksperimen yang akan memperoleh perlakuan pembelajaran RME dan kelompok kontrol yang akan mendapat pembelajaran konvensional.

Desain rencana penelitian untuk kelompok eksperimen sebagai berikut:

Kelas Eksperimen: $\quad 0 \quad X \quad O$

Kelas Kontrol:

O $\mathrm{O}$

Keterangan:

O: Pretes atau postes adaptive reasoning

$\mathrm{X}$ : Perlakuan pembelajaran $R M E$

Penelitian ini dilaksanakan di SMP Negeri 5 kota Tasikmalaya. Populasi penelitiannya adalah seluruh siswa SMP Negeri 5 kota Tasikmalaya pada tahun ajaran 2015/2016. Desain penelitian menggunakan desain kuasi-eksperimen maka penentuan sampel dilakukan dengan menggunakan teknik "Purposive Sampling", yaitu teknik pengambilan sampel berdasarkan pertimbangan tertentu (Sugiyono, 2005). Sampel pada penelitian ini terdiri dari dua kelompok siswa kelas IX yang dipilih secara purposive. Informasi awal dalam pemilihan sampel dilakukan berdasarkan pertimbangan dari guru bidang studi matematika. Agar penentuan sampel tidak bersifat subjektif, maka pertimbangan dalam menentukan sampel juga didasarkan pada perolehan nilai matematika siswa pada semester sebelumnya. Perolehan data dalam 
penelitian ini menggunakan instrumen tes berbentuk soal kemampuan adaptive reasoning.

\section{Hasil dan Pembahasan}

Analisis statistik yang digunakan untuk perbedaan peningkatan adaptive reasoning berdasarkan pembelajaran adalah Mann Whitney U dikarenakan data tidak berdistribusi normal. Berikut disajikan hasil uji normlitas pada Tabel 1.

Tabel 1.

Uji Normalitas Data Peningkatan adaptive reasoning

\begin{tabular}{llll|}
\hline Pembelajaran & $\mathbf{N}$ & Sig. & $\mathbf{H}_{\mathbf{0}}$ \\
\hline RME & 32 & 0.026 & ditolak \\
\hline Konvensional & 32 & 0.200 & diterima \\
\hline
\end{tabular}

Pada Tabel 1 terlihat bahwa kelas RME memiliki nilai signifikansi kurang dari 0,05 maka data tidak berdistribusi normal sedangkan kelas konvensional memiliki signifikansi lebih besar dari 0,05 sehingga data berdistribusi normal.

Tabel 2.

Uji Mann Whitney Data Peningkatan Adaptive Reasoning

\begin{tabular}{lclll|}
\hline Pembelajaran & Rerata & $\mathbf{Z}$ & Sig. & Ho $_{\mathbf{0}}$ \\
\hline RME & 0,44 & 5,49 & 0.000 & ditolak \\
\hline Konvensional & 0,32 & 5,49 & 0.000 & ditolak \\
\hline
\end{tabular}

Hasil uji Mann Whitney U pada Tabel.2 memperlihatkan nilai signifikansi sebesar 0,00 . Nilai ini kurang dari taraf signifikansi yakni 0,05 sehingga hipotesis nol ditolak yang artinya terdapat perbedaan rerata peningkatan adaptive reasoning antara kelompok pembelajaran RME dan kelompok konvensional.
Bila diperhatikan nilai rerata kelompok pembelajaran RME dan kelompok pembelajaran konvensional dapat pula disimpulkan bahwa secara keseluruhan peningkatan adaptive reasoning siswa yang mendapat pembelajaran RME lebih baik daripada peningkatan adaptive reasoning siswa yang mendapat pendekatan konvensional.

Setelah dilakukan uji normalitas terhadap data peningkatan adaptive reasoning berdasarkan kategori sekolah (atas dan menengah) dan kategori PAM (tinggi dan sedang) kelompok pembelajaran RME dan kelompok pembelajaran RME memiliki signifikansi lebih besar dari 0,05 maka semua datanya berdistribusi normal. Selanjutnya dilakukan uji homogenitas menggunakan uji Levene. Hasil pengujiannya dirangkum dalam Tabel 3.

Tabel 3.

Uji Homogenitas Data Peningkatan Adaptive Reasoning Setiap Kategori (PS dan PAM)

\begin{tabular}{lccccc|}
\hline Kategori & $\mathbf{F}$ & $\mathbf{d k 1}$ & $\mathbf{d k 2}$ & Sig. & $\mathbf{H}_{\mathbf{0}}$ \\
\hline Tinggi & 0,935 & 1 & 23 & 0,344 & Diterima \\
\hline Sedang & 0,596 & 1 & 73 & 0,443 & Diterima \\
\hline
\end{tabular}

Berdasarkan Tabel 3 diperoleh signifikansi semuanya lebih dari 0,05 maka hipotesisi nol diterima yang berarti bahwa tidak terdapat perbedaan variansi-variansi data. Tahap selanjutnya dilakukan uji-t pada kategori PAM (tinggi dan sedang).

Tabel 4.

Uji-t Data Peningkatan Adaptive Reasoning Setiap Kategori (PS dan PAM)

\begin{tabular}{cccccc}
\hline & Rerata & & T & Sig. & Ho $_{\mathbf{0}}$ \\
\hline $\begin{array}{c}\text { Kateg } \\
\text { ori }\end{array}$ & RME & $\begin{array}{c}\text { Konve } \\
\text { nsional }\end{array}$ & & & \\
& & & &
\end{tabular}




\begin{tabular}{|ccccccc|}
\hline $\begin{array}{c}\mathrm{P} \\
\mathrm{A}\end{array}$ & $\begin{array}{c}\text { Tin } \\
\text { ggi }\end{array}$ & 0,56 & 0,44 & 3,294 & 0,003 & $\begin{array}{c}\text { Ditol } \\
\text { ak }\end{array}$ \\
& $\begin{array}{c}\text { Sed } \\
\text { ang }\end{array}$ & 0,42 & 0,31 & 5,673 & 0,000 & $\begin{array}{c}\text { Ditol } \\
\text { ak }\end{array}$ \\
\hline
\end{tabular}

Pada Tabel 5 diperoleh semua nilai signifikansi kurang dari 0,05 maka tolak $\mathrm{H}_{0}$ dan terima $H_{1}$. Dengan demikian berarti bahwa terdapat perbedaan rerata peningkatan adaptive reasoning antara kelompok siswa yang belajar menggunakan RME dan kelompok siswa yang belajar menggunakan Konvensional.

Kategori PS (atas dan menengah) dan PAM (rendah) diuji menggunakan uji Mann Whitney U. Berikut disajikan hasil pengujiannya pada Tabel 5 .

Tabel 5.

Uji Mann Whitney U Data Peningkatan Adaptive Reasoning Setiap Kategori (PS dan PAM)

\begin{tabular}{|c|c|c|c|c|c|c|}
\hline \multicolumn{2}{|c|}{ Kategori } & \multicolumn{2}{|c|}{ Rerata } & \multirow[t]{2}{*}{ Z } & \multirow[t]{2}{*}{ Sig. } & \multirow[t]{2}{*}{$\mathrm{H}_{0}$} \\
\hline & & $\mathrm{RME}$ & Konv & & & \\
\hline \multirow{3}{*}{$\begin{array}{l}P \\
S\end{array}$} & Atas & 0,45 & 0,31 & $-4,407$ & 0,000 & Dito \\
\hline & & & & & & lak \\
\hline & $\begin{array}{c}\text { Mene } \\
\text { ngah }\end{array}$ & 0,42 & 0,33 & $-3,448$ & 0,001 & $\begin{array}{c}\text { Dito } \\
\text { lak }\end{array}$ \\
\hline$P$ & Rend & 0,47 & 0,24 & $-3,010$ & 0,003 & Dito \\
\hline A & ah & & & & & lak \\
\hline M & & & & & & \\
\hline
\end{tabular}

$\mathrm{H}_{0}$ : Tidak terdapat perbedaan rerata peningkatan adaptive reasoning

Berdasarkan Tabel 5 diperoleh nilai signifikansi semuanya kurang dari 0,05 maka $\mathrm{H}_{0}$ ditolak. Hal ini berarti bahwa terdapat perbedaan rerata peningkatan adaptive reasoning antara kelompok RME dan kelompok Konvensional berdasarkan kategori PS (atas dan menengah) dan PAM (rendah). Berikutnya dilakukan analisis terhadap data n-gain adaptive reasoning kelompok siswa yang memperoleh pembelajaran dengan pendekatan RME untuk melihat ada atau tidak adanya perbedaan peningkatan adaptive reasoning ditinjau dari kategori PS dan PAM. Pengujian PS menggunakan uji t atau uji $t^{\prime}$ atau Mann Whitney U. Pengujian PAM menggunakan ANAVA satu jalur atau uji Kruskal-Wallis.

Uji ANAVA satu jalur mengharuskan data memenuhi dua asumsi yaitu data harus berdistribusi normal dan semua data harus memiliki variansi yang homogen. Berdasarkan hasil pengujian normalitas terlihat bahwa untuk kategori PS dan PAM pada kelompok yang memperoleh pembelajaran RME terdapat data yang berdistribusi tidak normal. Dikarenakan asumsi kenormalan tidak terpenuhi baik oleh kategori PS dan PAM maka PS diuji dengan Mann Whitney $U$ sedangkan PAM diuji dengan menggunakan uji Kruskal Wallis.

Hasil uji Mann Whitney $U$ dan Kruskal Walis akan menunjukkan apakah terdapat perbedaan rerata skor $n$-gain adaptive reasoning yang signifikan antara kelompok-kelompok yang memperoleh pembelajaran RME berdasarkan kategori PS dan PAM. Hasil pengujiannya disajikan pada Tabel 6.

Tabel 6.

Uji Mann Whitney U Skor Postes Adaptive Reasoning Kelompok Pembelajaran RME berdasarkan Kategori PS

\begin{tabular}{cccc}
\hline Kategori & $\mathbf{Z}$ & Sig. & $\mathbf{H}_{\mathbf{0}}$ \\
\hline PS & $-0,766$ & 0,443 & Diterima
\end{tabular}

$\mathrm{H}_{0}$ : Tidak terdapat perbedaan peningkatan Adaptive Reasoning 
Tabel 7.

Uji Kruskal Wallis Skor Postes Adaptive Reasoning Kelompok Pembelajaran RME berdasarkan Kategori PAM

\begin{tabular}{lcccc}
\hline Kategori & Chi-Square & Df & Sig. & $\mathbf{H}_{\mathbf{0}}$ \\
\hline PAM & 24,483 & 2 & 0,00 & Ditolak \\
$\mathrm{H}_{0}:$ Tidak & terdapat & perbedaan & peningkatan \\
adaptive reasoning & & &
\end{tabular}

Diperoleh nilai signifikansi (sig) untuk kategori PS lebih dari 0,05 maka disimpulkan tidak terdapat perbedaan peningkatan adaptive reasoning. Pada kategori PAM diperoleh signifikansi kurang dari 0,05. Dengan demikian disimpulkan untuk kategori PAM yaitu paling sedikit ada dua kelompok siswa yang belajar dengan pembelajaran RME pada kategori PAM yang memiliki rerata peningkatan adaptive reasoning yang berbeda secara signifikan.

\section{Penutup}

Berdasarkan hasil uji perbedaan rerata dan besarnya nilai rerata peningkatan adaptive reasoning antara kedua kelompok pembelajaran (RME dan Konvensional) dilihat dari kategori PS dan PAM dapat disimpulkan bahwa: 1. Peningkatan adaptive reasoning siswa kategori PS atas yang memperoleh pembelajaran RME lebih baik daripada siswa yang memperoleh pembelajaran Konvensional. 2. Peningkatan adaptive reasoning siswa kategori PS menengah yang memperoleh pembelajaran RME lebih baik daripada siswa yang memperoleh pembelajaran Konvensional.

3. Peningkatan adaptive reasoning siswa kategori PAM tinggi yang memperoleh pembelajaran RME lebih baik daripada siswa yang memperoleh pembelajaran Konvensional. 4. Peningkatan adaptive reasoning siswa kategori PAM sedang yang memperoleh pembelajaran RME lebih baik daripada siswa yang memperoleh pembelajaran Konvensional.

\section{UCAPAN TERIMA KASIH}

Saya ucapkan terima kasih kepada pimpinan Universitas Galuh dan pihak SMP Negeri 5 Kota Tasikmalaya yang telah memberikan kesempatan dan fasilitas kepada peneliti selama melakukan penelitian.

\section{Daftar Pustaka}

Gravemeijer, K. (2004). Local Instructional Theories as Means of Support for Teacher in Reform Mathematics Education. Mathematical Thinking and Learning. 6(2), 105-128. Lawrence Erlbaum Association, Inc.

Hudojo, H. (2004). Pengembangan Kurikulum dan Pembelajaran Matematika. Universitas Malang: Japan International Cooperation Agency.

Killpatrick, J., Swafford, J., dan Findell, B. (2001). Adding it up: Helping children Learn Mathematics. Washington, DC: National Academy Press.

Rianasari, V.F, Budayasa, I, Patahudin, S.M. (2012). Supporting Students' Understanding of Percentage. Jurnal JME IndoMS vol. 3 No. 1 January 2012, pp.29-40

Ruseffendi, E. T. (2010). Pengantar Kepada membantu guru Mengembangkan Kompetensinya dalam Pengajaran 
Matematika untuk meningkatkan CBSA. Bandung: Tarsito.

Suryadi dan Suratno. (2014). Kemandirian

Pendidik. Kisah Pendidik Reflektif dan Profesional Pembelajaran. SPs UPI. Bandung.

\section{Riwayat Hidup PenUlis}

\section{Ida Nuraida, S.Pd. M.Pd.}

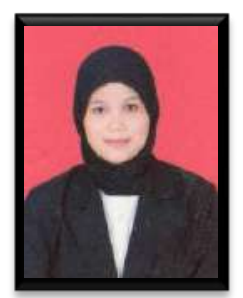

Lahir di Kota tasikmalaya, 2 Agustus 1979. Staf pengajar di institusi Universitus Galuh Ciamis FKIP Program Studi Pendidikan Matematika (Menjabat Ketua Prodi Pendidikan Matematika). Studi S1 Pendidikan Matematika Universitas Siliwangi Tasikmalaya, lulus tahun 2003; S2 Pendidikan Matematika UPI Bandung lulus tahun 2013; dan S3 Pendidikan Matematika UPi bandung (on going). 
This page is intentionally left blank 